\title{
PHYTOCHEMICALS AND IDENTIFICATION OF ANTIOXIDANT COMPOUNDS FROM ETHANOL EXTRACT OF SONNERATIA ALBA LEAVES AND BARK
}

\author{
Sasmito Bambang Budi ${ }^{1 \star}$, Sulistiyati Titik Dwi ${ }^{2}$, Hardoko ${ }^{1}$ \\ ${ }^{1}$ Department of Fisheries Tech, Faculty of Fisheries and Marine Science, \\ University of Brawijaya, Malang, Indonesia \\ ${ }^{2}$ Department of Aquatic Resource Management, Faculty of Fisheries and Marine Science, \\ University of Brawijaya, Malang, Indonesia \\ *E-mail: niabbs@yahoo.com
}

\begin{abstract}
The purpose of this study was the bioactive identification of ethanol extracts $(\mathrm{EtOH})$ from the bark and leaves of Sonneratia alba that have antioxidant activity. Mangrove bark and leaf powder each added with ethanol $(1: 3, \mathrm{w} / \mathrm{v})$ sonicated for 10 minutes. The obtained extract was tested for phytochemicals, antioxidant activity using DPPH and identification of the compounds using UPLC-ESI-MS. The ethanol extract from the bark and leaves of $S$. alba contains bioactive compounds that have antioxidant activity from the group of phenol compounds and the both extracts contain 7-hydroxycoumarin or scopoletin. The antioxidant activity $\left(\mathrm{IC}_{50}\right.$ value) of each extract was $67,211 \pm 2,482 \mu \mathrm{g} / \mathrm{ml}$ and $88,706 \pm 4,782 \mu \mathrm{g} / \mathrm{ml}$, respectively. Ethanol extract from bark and leaves of $S$. alba has the potential to be an antioxidant agent.
\end{abstract}

\section{KEY WORDS}

Antioxidant, bark, ethanol extract, leaves, Sonneratia alba.

The superiority of natural antioxidant has been proven and there is no doubt that besides its ability to break free chain reactions, it is also relatively safe to use. The natural antioxidants are increasingly needed in the health, pharmaceutical and other industries, including the food and beverage industry. At least the last two decades, the demand for bioactive compounds has increased rapidly, especially antioxidant compounds must be balanced by exploring resources.

Mangroves are a potential source of natural antioxidants, where this plant is one of the abundant biological resources in Indonesia. Research into the use of this plant shows rapid progress, especially in the last two decades. Some families such as Rhizopora, Avicennia, Bruguiera and Sonneratia are reported as additional bioactive sources. Rhizopora spp mangroves have been tested and used for functional nutrition, namely antidiabetics and strong antioxidants (Hardoko, Puspitasari and Suprayitno, 2015). The fruit of Avicennia marina is known to contain a lot of triterpenoid saponins which have anti-tumor activity (Yang et al., 2019). In addition to the fruit pericarp, Sonneratia apetala seeds have the potential as a source of antioxidants, antidiabetics and antibacterial compounds (Hossain et al., 2013). Similarly, hypocotyl of Bruguiera gymnorrhiza was found to contain many compounds of terpene, triterpenes, flavonoids and aromatics as secondary metabolites with relatively high antioxidant activity (Nebula, Harisankar and Chandramohanakumar, 2013; Yao et al., 2017). The leaves, fruit and bark of some mangrove plants are reported to contain bioactives as antimicrobial, antidiabetic, anti-inflammatory, antitumor and antioxidant. Most bioactive substances, including antioxidants from mangroves, are phenolic compounds, e.i. coumarine. As one of the phenolic compounds that had an antioxidant, antibacterial, analgesic and anti-inflammatory effect.

Sonneratia alba is known to contain antioxidants and can be used as a functional food for diabetics. While the leaves and bark have the potential to be used as tea and functional drinks. However, there is no information available on antioxidant bioactive compounds in the leaf and bark extract of the plant. In this study, antioxidant compounds in $\mathrm{EtOH}$ extracts of $S$. alba leaves and bark were identified using UPLC-ESI-MS. 


\section{MATERIALS AND METHODS OF RESEARCH}

Fresh Sonneratia alba bark and leaves were collected from Probolinggo East Java and used to retrieve their extracts. The bark and leaves were rinsed thoroughly with tap water, followed by distilled water to remove the dust and other particles, air dried and sliced into small pieces. $20 \mathrm{~g}$ of finely cut bark and leaves were weighed and put into $250-\mathrm{mL}$ Erlenmeyer flask containing $160 \mathrm{~mL}$ ethanol and sonicated for $10 \mathrm{~min}$. The crude extract obtained was filtered and removed the solvent by rotary evaporator for $30 \mathrm{~min}$. For all work was replicated for 3 times. Ethanol extract of bark (EEB) and leaf (EEL) were used to the sample for determine of phytochemical, total poliphenol content (TPC) and antioxidant activity (DPPH, radical scavenging abillity). The antioxidant compounds were determined by LC-MS. EtOH of sample were screened for the presence of alkaloids, flavonoids, terpenoids, steroids, phenolics, saponins and tannins (Harborne, 1984). It was done to assess the qualitative chemical composition of crude extracts using commonly employed precipitation and discoloration reaction. General reactions in these analyses revealed the presence or absence of these compounds in the crude extracts.

The phenolic content (TPC) in the EtOH extract were determined by the Folinceocalteu reagent (Sasmito et al., 2013). $250 \mu$ l extract was added with $1250 \mu$ l aquades, $250 \mu \mathrm{l}$ ethanol and $125 \mu \mathrm{l}$ Folin-ceocalteu reagents. The mixture was incubated at room temperature for $5 \mathrm{~min}$, added $250 \mu \mathrm{l} 5 \% \mathrm{Na}_{2} \mathrm{CO}_{3}$, and stored in a dark room for a hour. Absorbance was measured by using a spectrophotometer at $\lambda 725 \mathrm{~nm}$. TPC was calculated based on the standard formula (gallic acid), $y=0.0085 x-0.018$ and expressed in $\mathrm{mg}$ gallic acid equivalent per $g$ sample.

The antioxidant activity of the $\mathrm{EtOH}$ extract from the bark and leaf of $S$. alba were determined using DPPH radical scavenging assay according to the method used (Sasmito et al., 2013). Each aliquot $(0.1 \mathrm{ml})$ of the sample with varying concentrations $(25,50,100$ and $200 \mu \mathrm{g} / \mathrm{ml}$ ) was added to $3.0 \mathrm{ml}$ of DPPH ethanol solution, shaken and stored for 30 minutes in a dark room. The scavenging effect on DPPH radicals was determined by spectrophotometer at $\lambda 517 \mathrm{~nm}$. DPPH is calculated by the following equation:

$$
\text { Percentage of the RSA }=\frac{A c-A s}{A c} \times 100 \%
$$

Where: $A_{C}=$ absorbance of control and $A_{S}=$ absorbance of the sample. The DPPH solution without sample solution was used as control. $I_{50}$ value is the concentration of sample required to scavenge $50 \%$ of DPPH free radical and was calculated by using the plotted graph of radical scavenging activity (RSA) against the concentration of samples.

Bioactive compounds were investigated using liquid chromatography instruments (ACQUITY UPLCH-Class System, Water, USA) with a C18 column $(1.8 \mu \mathrm{m} 2.1 \times 100 \mathrm{~mm})$. Mass spectrometry: Electropray ionization (ESI), positive ion. Mass analysis range: $50-1200$ $\mathrm{m} / \mathrm{z}$. A total of $5 \mu \mathrm{l}$ of the sample were injected and through the first $0.2 \mu \mathrm{l}$ syringe filter. Mobile phase: water $+5 \mathrm{mM}$ format ammonium and acetonitrile $+0.05 \%$ formic acid; flow rate: $0.2 \mathrm{ml} / \mathrm{min}$ gradually for 18 minutes. The mass spectrum of compounds was analyzed using Masslynx software to obtain molecular formulas (compounds and their relative masses), and then the determination of compounds was confirmed with data bases at Chemspider, Massbank, and others. Except for the identification of antioxidant compounds by LCMS, all analyzes were carried out and repeated three times. The results of data analysis are displayed as the mean values \pm standard deviation (S.D); and linear regression analysis and calculation were done by using MS-Excel software.

\section{RESULTS AND DISCUSSION}

The ethanolic extract from $S$. alba bark and leaves was $9.37 \pm 0.19 \%$ and $10.26 \pm$ $0.29 \%$, with a moisture content of $17.50 \pm 0.07 \%$ and $19.30 \pm 0.03 \%$, respectively. In 
addition, the results of the phytochemical analysis of ethanolate extracts are both shown in Table 1.

Table 1 - Phytochemical, antioxidant activity $\left(\mathrm{IC}_{50}\right)$ and total phenol of the EtOH extract

\begin{tabular}{|c|c|c|c|}
\hline Compounds & & Bark & Leaves \\
\hline Alcaloids & & - & - \\
\hline Flavonoids & & +++ & ++ \\
\hline Terpenoids & & ++ & + \\
\hline Steroids & & + & - \\
\hline Phenolics & & ++ & ++ \\
\hline Saponins & & ++ & ++ \\
\hline Tannins & & ++ & + \\
\hline Antioxidant activity & $\mathrm{IC}_{50}(\mu \mathrm{g} / \mathrm{ml})$ & $67.211 \pm 2.482$ & $88.706 \pm 4.782$ \\
\hline Total phenolic content & $\mathrm{mgGAE} / \mathrm{g}$ & $10.248 \pm 0.174$ & $5.847 \pm 0.315$ \\
\hline
\end{tabular}

The EtOH extract from $S$. alba bark was not contain alkaloids but positively contains flavonoids, terpenoids, steroids, phenolics and tannins. Whereas the extract from $S$. alba leaves, besides showing no alkaloid content, also the presence of steroid compounds was not detected (Table 1). Furthermore, the antioxidant activity of ethanolate extract from the bark and leaves of $S$. alba to scavenge a free radical (DPPH) is very strong. The $\mathrm{IC}_{50}$ values of each of the above extracts were $67,211 \pm 2,482 \mu \mathrm{g} / \mathrm{ml}$ and $88,706 \pm 4,782 \mu \mathrm{g} / \mathrm{ml}$, respectively. The total content of polyphenols in the bark extract was $10.248 \pm 0.174$ $\mathrm{mgGAE} / \mathrm{g}$ sample, while the $\mathrm{EtOH}$ extract of mangrove leaves contained a total polyphenol of $5.847 \pm 0.315 \mathrm{mgGAE} / \mathrm{g}$ sample.

The types of antioxidant compounds detected in the leaves of EtOH extract were fewer than those found in the bark extract. Bioactive compounds suspected of having antioxidant activity of mangrove bark are approximately 8 compounds; whereas only about 5 antioxidant compounds were detected in mangrove leaves (Table 2 ).

Table 2 shows that 7-hydroxycoumarin $\left(\mathrm{C}_{9} \mathrm{H}_{6} \mathrm{O}_{3}\right)$ was detected at the earliest retention time (Rt $4.22 \mathrm{~min}$ ). As an organic compound, hydroxycoumarin is found in many types of plants and are widely distributed in parts such as leaves, stems and roots of plants. These compound is also called umbelliferone, as derivative compound of coumarin which has antioxidant, antibacterial and antifungal activities (Repčák, Imrich and Franeková, 2001; Abdel-Farid, Sheded and Mohamed, 2014; Witaicenis et al., 2014; Mazimba, 2017). Coumarin is a phenolic compound found in many plants that has been known to have good antioxidant activity, and is soluble in polar solvents such as methanol and ethanol (Yang and Lee, 2012). This is supported by the results of phytochemical analysis (Table 1) which shows the presence of phenolic compounds in the $\mathrm{EtOH}$ extracts of bark and $S$. alba leaves. Coumarin has antioxidant activity as reported by Wang (Wang et al., 2016) and also has activity as an antitumor and antihyperlipidemic (lyer and Patil, 2014).

Table 2 - Results of identification of antioxidant compounds in $\mathrm{EtOH}$ extracts

\begin{tabular}{|c|c|c|c|c|}
\hline Source & $\mathrm{Rt}$ & $\mathrm{m} / \mathrm{z}(\mathrm{Da})$ & Mol formula & Compounds \\
\hline \multirow{9}{*}{ Bark } & 4.22 & 162.032 & $\mathrm{C}_{9} \mathrm{H}_{6} \mathrm{O}_{3}$ & 7-hydroxycoumarin \\
\hline & 4.76 & 138.121 & $\mathrm{C}_{7} \mathrm{H}_{6} \mathrm{O}_{3}$ & 3-hydroxybenzoic acid, or Salicylic acid \\
\hline & 4.79 & 306.074 & $\mathrm{C}_{15} \mathrm{H}_{14} \mathrm{O}_{7}$ & Epigallocatechin \\
\hline & 5.096 & 578.520 & $\mathrm{C}_{30} \mathrm{H}_{26} \mathrm{O}_{12}$ & Procyanidin B1 or B2 \\
\hline & 6.689 & 170.120 & $\mathrm{C}_{7} \mathrm{H}_{6} \mathrm{O}_{5}$ & Gallic acid \\
\hline & \multirow{2}{*}{7.406} & 236.265 & $\mathrm{C}_{16} \mathrm{H}_{12} \mathrm{O}_{2}$ & 3-benzyl-2H-chromen-2-one, or Coumarin \\
\hline & & 328.359 & $\mathrm{C}_{19} \mathrm{H}_{20} \mathrm{O}_{5}$ & Decursin or acutilobin \\
\hline & 7.509 & 278.302 & $\mathrm{C}_{18} \mathrm{H}_{14} \mathrm{O}_{3}$ & Tanshinone \\
\hline & 8.057 & 344.272 & $\mathrm{C}_{17} \mathrm{H}_{12} \mathrm{O}_{8}$ & 2,3,8-tri-O-methylellagic acid \\
\hline \multirow{5}{*}{ Leaves } & 4.22 & 162.032 & $\mathrm{C}_{9} \mathrm{H}_{6} \mathrm{O}_{3}$ & 7-hydroxycoumarin, \\
\hline & 4.84 & 256.253 & $\mathrm{C}_{15} \mathrm{H}_{12} \mathrm{O}_{4}$ & Isoliquiritigenin, \\
\hline & 5.06 & 300.263 & $\mathrm{C}_{16} \mathrm{H}_{12} \mathrm{O}_{6}$ & Diosmetin \\
\hline & 5.46 & 318.235 & $\mathrm{C}_{15} \mathrm{H}_{10} \mathrm{O}_{8}$ & Merycetin, Gossypetin, Quercetagetin \\
\hline & 6.64 & 286.236 & $\mathrm{C}_{15} \mathrm{H}_{10} \mathrm{O}_{6}$ & Luteolin \\
\hline
\end{tabular}

Note: *Retention times (min). 
Salicylic acid $\left(\mathrm{C}_{7} \mathrm{H}_{6} \mathrm{O}_{3}\right)$ is a secondary metabolite of plants that has anti-inflammatory, anti-fungal and antibacterial activity. Salisilic acid is a hydroxybenzoic acid in which bensoic acid with a hydroxyl group is in the ortho position(National Center for Biotechnology Information., 2019).

Epigallocatechin $\left(\mathrm{C}_{15} \mathrm{H}_{14} \mathrm{O}_{7}\right)$, a phenolic compound that has strong antioxidant activity, and is widely found in plant leaves including mangroves. Rios (2005) has reported that methanol extracts from Acacia pennatula leaves were detected containing catechins and epigallocatechin compounds. Epigallocatechin and catechin derivatives are also found in many plant leaf extracts, like as reported by Romani et al. (1999), that the leaves of Myrtus communis also contain many catechin derivatives.

Isomeric of $\mathrm{C}_{30} \mathrm{H}_{26} \mathrm{O}_{12}(+)$-procyanidin $\mathrm{B} 1$ from $\mathrm{B} 2$ and (+)-catechins including polyphenol compounds found in many parts of plants as reported (Du et al., 2013). This compound has a high ability to reduce free radicals. ESI-MS analysis showed the main molecular weight of procyanidin with a peak value of $[\mathrm{M}+\mathrm{H}]+$ was 579.2 . This means that the extract contains a dimer from procyanidin, and epicatechin as its basic unit (Ling, Xie and Yang, 2005).

Coumarin, 3-benzyl-2H-chromium-2-one $\left(\mathrm{C}_{16} \mathrm{H}_{12} \mathrm{O}_{2}\right)$, coumarin is a heterocyclic molecule that is often associated with its benefits for human health, such as reducing the risk of cancer, diabetes and heart disease. This effect is associated with the effect of capturing free radicals, due to their antioxidant activity. The clean-up effect of the free radical 2,2diphenyl-1-picrillidrazil (DPPH) shows high activity with a low $\mathrm{IC}_{50}$ value (Li et al., 2012).

Decursin or acutilobin is a coumarin derivate compound $\left(\mathrm{C}_{19} \mathrm{H}_{20} \mathrm{O}_{5}\right)$. This compound belongs to the class of coumarin derivatives known as linear pyranocoumarin. This is an organic compound containing pyran ring which linearly joins to the coumarin section. Coumarin is a phenolic compound that is naturally synthesized by several plant species. Coumarin and its derivatives have been found to have significant anti-inflammatory and antioxidant activity (Kontogiorgis, Savvoglou and Hadjipavlou-Litina, 2006). Acutilobin is a coumarin derivative that also has biological activity as an antitumor (anticancer), and some coumarin derivatives have also been found to have the ability to scavenge reactive oxygen species (ROS) - free radicals (Kadhum et al., 2011).

Furthermore tanshinone $\left(\mathrm{C}_{18} \mathrm{H}_{14} \mathrm{O}_{3}\right)$ is an organic compound from the prenol-lipid class that is terpenoid which also has good biological activity as an antioxidant. The quinone compound that is thought to be present in the ethanol extract of mangrove bark has been used as a natural medicine in China. Dried root Salvia miltiorrhiza Bunge is a herbal medicine that is very commonly used in several regions in China. Besides S. miltiorrhiza Bunge (purple flowering) also other varieties with white flowers, S. miltiorrhiza Bunge $f$. Alba (Zhang et al., 2016). Tansinon, besides having antioxidant activity is also reported to have anti-tumor activity (Yoon et al., 1999; Lee et al., 2010).

Another polyphenol compound detected in the $S$. alba bark extract is $\mathrm{C}_{17} \mathrm{H}_{12} \mathrm{O}_{8}(2,3,8$ tri-O-methylellagic acid). These compounds found in plants that are widely distributed. The amount of $\mathrm{MeOH}$ solubles in both bark and wood from young trees Eucalyptus globulus, $E$. Regnansand E. Deglupta showed the presence ellagic compound (Yazaki and Hillis, 1976). It is contained in the leaves of Phyllanthus reticulatus as part of the metabolites extracted in dichlorometan (Pojchaijongdee et al., 2010). This compound is also contained in the bark of the Irvingia gabonensis plant and is thought to have anti-bacterial activity (Ndukwe and Zhao, 2007).

Furthermore, the bioactive compounds suspected of being natural antioxidants in $S$. alba leaves beside the 6-Methoxy-7-hydroxycoumarin, are: Isoliquiritigenin is a flavonoid (isoflavan) which has bioactive potential as an anti-inflammatory, anti-bacterial and antioxidant (Trinh et al., 2015; Xiao et al., 2017). This compound is also widely found in plants such as Glycyrrhiza uralensis as reported by Watanabe (Watanabe et al., 2016).

Diosmetin $\left(\mathrm{C}_{16} \mathrm{H}_{12} \mathrm{O}_{6}\right)$ or 3',5,7-trihydroxy-4'-methoxyflavone) is the aglycone portion of the diosmin flavonoid glycosides. A phenolic compound like flavonoids, that is also found in many fruit peels, flowers and medicinal plants such as Chionanthus retusus (Oleaceae) (Patel et al., 2013; Lee et al., 2019). 
$\mathrm{C}_{15} \mathrm{H}_{10} \mathrm{O}_{8}$ (merycetin, gossypetin, quercetagetin), merisitin, gossypetin are phenolic compounds which are derivatives of flavonoids-glucosides, many of which are found in plant material such as cactus rind, white berries (Myrtus communis L. var, leucocarpa DC) and others (Fernández-López et al., 2010; Serreli et al., 2017). Quercetagetin is flavonol which is also widely found in plant matter and has antioxidant activity. These compounds besides having antioxidant activity, are also anti-diabetic, antiproliferation and others (Loizzo et al., 2009; Zehl et al., 2011; Wang et al., 2016).

$\mathrm{C}_{15} \mathrm{H}_{10} \mathrm{O}_{6}$ (Luteolin), is a tetrahydroxyflavone which is basically a planar molecule and contains intramolecular hydrogen bonds (Cox et al., 2003). Luteolin is a flavon that has a hydroxyl group in ring $B$ and is an isomer of epigenin, and inhibits oxidative stress (Huang et al., 2013).

\section{CONCLUSION}

The antioxidant compounds in the ethanol extract of Sonneratia alba bark, quantitatively, have more types and contents than ethanol extracts from their leaves. Polyphenols are the constituents in both of the ethanol extracts (bark and leaves) which have antioxidant activities.

\section{ACKNOWLEDGEMENTS}

The author would like to express appreciation and thanks to Gessy and Loryanti, that they have helped with data collection.

\section{REFERENCES}

1. Abdel-Farid, I. B., Sheded, M. G. and Mohamed, E. A. (2014) 'Metabolomic profiling and antioxidant activity of some Acacia species', Saudi Journal of Biological Sciences. King Saud University, 21(5), pp. 400-408. doi: 10.1016/j.sjbs.2014.03.005.

2. Cox, P. J., Kumarasamy, Y., Nahar, L., Sarker, S. D. and Shoeb, M. (2003) 'Luteolin', Acta Crystallographica Section E, 59(7), pp. 0975--0977. doi: $10.1107 / S 1600536803013229$.

3. Du, H., Wu, J., Li, H., Zhong, P.-X., Xu, Y.-J., Li, C.-H., Ji, K.-X. and Wang, L.-S. (2013) 'Polyphenols and triterpenes from Chaenomeles fruits: Chemical analysis and antioxidant activities assessment', Food Chemistry, 141(4), pp. 4260-4268. doi: https://doi.org/10.1016/j.foodchem.2013.06.109.

4. Fernández-López, J. A., Almela, L., Obón, J. M. and Castellar, R. (2010) 'Determination of Antioxidant Constituents in Cactus Pear Fruits', Plant Foods for Human Nutrition, 65(3), pp. 253-259. doi: 10.1007/s11130-010-0189-x.

5. Harborne, J. B. (1984) Phytochemical Methods: A Guide to Modern Techniques of Plant Analysis. second ed., Chapman and Hall, New York, USA., Chapmer and Hall.

6. Hardoko, Puspitasari, Y. E. and Suprayitno, E. (2015) 'a-glucosidase inhibitory activities of Rhizophora mucronata fruitpowder', International Journal of ChemTech Research, 8(1), pp. 211-215.

7. Hossain, S. J., Basar, M. H., Rokeya, B., Arif, K. M. T., Sultana, M. S. and Rahman, M. $H$. (2013) 'Evaluation of antioxidant, antidiabetic and antibacterial activities of the fruit of Sonneratia apetala (Buch.-Ham.)', Oriental Pharmacy and Experimental Medicine, 13(2), pp. 95-102. doi: 10.1007/s13596-012-0064-4.

8. Huang, C.-S., Lii, C.-K., Lin, A.-H., Yeh, Y.-W., Yao, H.-T., Li, C.-C., Wang, T.-S. and Chen, H.-W. (2013) 'Protection by chrysin, apigenin, and luteolin against oxidative stress is mediated by the Nrf2-dependent up-regulation of heme oxygenase 1 and glutamate cysteine ligase in rat primary hepatocytes', Archives of Toxicology, 87(1), pp. 167-178. doi: 10.1007/s00204-012-0913-4.

9. Iyer, D. and Patil, U. K. (2014) 'Evaluation of antihyperlipidemic and antitumor activities of isolated coumarins from Salvadora indica', Pharmaceutical Biology. Taylor \& Francis, 
52(1), pp. 78-85. doi: 10.3109/13880209.2013.815633.

10. Kadhum, A. A. H., Al-Amiery, A. A., Musa, A. Y. and Mohamad, A. B. (2011) 'The Antioxidant Activity of New Coumarin Derivatives', International Journal of Molecular Sciences . doi: 10.3390/ijms12095747.

11. Kontogiorgis, C. A., Savvoglou, K. and Hadjipavlou-Litina, D. J. (2006) 'Antiinflammatory and antioxidant evaluation of novel coumarin derivatives', Journal of Enzyme Inhibition and Medicinal Chemistry. Taylor \& Francis, 21(1), pp. 21-29. doi: $10.1080 / 14756360500323022$.

12. Lee, W. Y. W., Cheung, C. C. M., Liu, K. W. K., Fung, K. P., Wong, J., Lai, P. B. S. and Yeung, J. H. K. (2010) 'Cytotoxic Effects of Tanshinones from Salvia miltiorrhiza on Doxorubicin-Resistant Human Liver Cancer Cells', Journal of Natural Products. American Chemical Society, 73(5), pp. 854-859. doi: 10.1021/np900792p.

13. Lee, Y.-G., Lee, H., Jung, J.-W., Seo, K.-H., Lee, D. Y., Kim, H.-G., Ko, J.-H., Lee, D.-S. and Baek, N.-I. (2019) 'Flavonoids from Chionanthus retusus (Oleaceae) Flowers and Their Protective Effects against Glutamate-Induced Cell Toxicity in HT22 Cells', International journal of molecular sciences. MDPI, 20(14), p. 3517. doi: 10.3390/ijms20143517.

14. Li, G.-Q., Li, Y.-L., Jiang, T., Jiang, R.-W. and Wang, G.-C. (2012) '3-Benzyl-2\{lit H\}chromen-2-one', Acta Crystallographica Section E, 68(5), p. 01504. doi: $10.1107 / \mathrm{S} 1600536812014298$.

15. Ling, Z.-Q., Xie, B.-J. and Yang, E.-L. (2005) 'Isolation, Characterization, and Determination of Antioxidative Activity of Oligomeric Procyanidins from the Seedpod of Nelumbo nucifera Gaertn.', Journal of Agricultural and Food Chemistry. American Chemical Society, 53(7), pp. 2441-2445. doi: 10.1021/jf040325p.

16. Loizzo, M. R., Said, A., Tundis, R., Hawas, U. W., Rashed, K., Menichini, Federica, Frega, N. G. and Menichini, Francesco (2009) 'Antioxidant and Antiproliferative Activity of Diospyros lotus L. Extract and Isolated Compounds', Plant Foods for Human Nutrition, 64(4), p. 264. doi: 10.1007/s11130-009-0133-0.

17. Mazimba, O. (2017) 'Umbelliferone: Sources, chemistry and bioactivities review', Bulletin of Faculty of Pharmacy, Cairo University. Faculty of Pharmacy, Cairo University, 55(2), pp. 223-232. doi: 10.1016/j.bfopcu.2017.05.001.

18. National Center for Biotechnology Information. (2019) Salicylic acid. PubChem Database. Available at: https://pubchem.ncbi.nlm.nih.gov/compound/Salicylic-acid.

19. Ndukwe, G. I. and Zhao, Y. (2007) 'Pharmacological activity of 2,3,8-tri-O-methyl ellagic acid isolated from the stem bark of Irvingia gabonensis', African Journal of Biotechnology (ISSN: 1684-5315) Vol 6 Num 16, 6. doi: 10.5897/AJB2007.000-2288.

20. Nebula, M., Harisankar, H. S. and Chandramohanakumar, N. (2013) 'Metabolites and bioactivities of Rhizophoraceae mangroves', Natural Products and Bioprospecting, 3(5), pp. 207-232. doi: 10.1007/s13659-013-0012-0.

21. Patel, K., Gadewar, M., Tahilyani, V. and Patel, D. K. (2013) 'A review on pharmacological and analytical aspects of diosmetin: A concise report', Chinese Journal of Integrative Medicine, 19(10), pp. 792-800. doi: 10.1007/s11655-013-1595-3.

22. Pojchaijongdee, N., Sotanaphun, U., Limsirichaikul, S. and Poobrasert, O. (2010) 'Geraniinic acid derivative from the leaves of Phyllanthus reticulatus', Pharmaceutical Biology. Taylor \& Francis, 48(7), pp. 740-744. doi: 10.3109/13880200903273898.

23. Repčák, M., Imrich, J. and Franeková, M. (2001) 'Umbelliferone, a stress metabolite of Chamomilla recutita (L.) Rauschert', Journal of Plant Physiology, 158(8), pp. 1085-1087. doi: https://doi.org/10.1078/0176-1617-00284.

24. Rios, M. Y. (2005) 'Terpenes, coumarins, and flavones from Acacia pennatula', Chemistry of Natural Compounds, 41(3), pp. 297-298. doi: 10.1007/s10600-005-0133-8.

25. Romani, A., Pinelli, P., Mulinacci, N., Vincieri, F. F. and Tattini, M. (1999) 'Identification and quantitation of polyphenols in leaves of Myrtus communis L.', Chromatographia, 49(1-2), pp. 17-20. doi: 10.1007/BF02467181.

26. Sasmito, B. B., Kumalaningsih, S., W, S. and Hardoko (2013) 'Polyphenol Content and Antioxidant Activities of Crude Extract from Brown Algae by Various Solvents', J. Life Sci. 
Biomed, 3(6), pp. 439-443.

27. Serreli, G., Jerković, I., Gil, K. A., Marijanović, Z., Pacini, V. and Tuberoso, C. I. G. (2017) 'Phenolic Compounds, Volatiles and Antioxidant Capacity of White Myrtle Berry Liqueurs', Plant Foods for Human Nutrition, 72(2), pp. 205-210. doi: 10.1007/s11130017-0611-8.

28. Trinh, P. T. N., Tri, M. D., An, N. H., An, P. N., Minh, P. N. and Dung, L. T. (2015) 'Phenolic Compounds from the Rhizomes of Drynaria bonii', Chemistry of Natural Compounds, 51(3), pp. 476-479. doi: 10.1007/s10600-015-1318-4.

29. Wang, W., Xu, H., Chen, H., Tai, K., Liu, F. and Gao, Y. (2016) 'In vitro antioxidant, antidiabetic and antilipemic potentials of quercetagetin extracted from marigold (Tagetes erecta L.) inflorescence residues', Journal of Food Science and Technology, 53(6), pp. 2614-2624. doi: 10.1007/s13197-016-2228-6.

30. Watanabe, Y. et al. (2016) 'Isoliquiritigenin Attenuates Adipose Tissue Inflammation in vitro and Adipose Tissue Fibrosis through Inhibition of Innate Immune Responses in Mice', Scientific Reports. Nature Publishing Group, 6(March), pp. 4-6. doi: 10.1038/srep23097.

31. Witaicenis, A., Seito, L. N., da Silveira Chagas, A., de Almeida, L. D., Luchini, A. C., Rodrigues-Orsi, P., Cestari, S. H. and Di Stasi, L. C. (2014) 'Antioxidant and intestinal anti-inflammatory effects of plant-derived coumarin derivatives', Phytomedicine, 21(3), pp. 240-246. doi: https://doi.org/10.1016/j.phymed.2013.09.001.

32. Xiao, Z., Tao, S., Yang, Y. and Zhang, Y. (2017) 'A New Isoflavan from Abrus precatorius', Chemistry of Natural Compounds, 53(2), pp. 257-259. doi: 10.1007/s10600017-1965-8.

33. Yang, J.-Y. and Lee, H.-S. (2012) 'Evaluation of antioxidant and antibacterial activities of morin isolated from mulberry fruits (Morus alba L.)', Journal of the Korean Society for Applied Biological Chemistry, 55(4), pp. 485-489. doi: 10.1007/s13765-012-2110-9.

34. Yang, X.-W., Dai, Z., Wang, B., Liu, Y.-P., Zhao, X.-D. and Luo, X.-D. (2018) 'Antitumor Triterpenoid Saponin from the Fruits of Avicennia marina', Natural Products and Bioprospecting. Springer Singapore, 8(5), pp. 347-353. doi: 10.1007/s13659-018-0167-9.

35. Yao, J. E., Shen, M. R., Yi, X. X., Yang, Y. and Gao, C. H. (2017) 'A new 8hydroxyquercetagetin glycoside from the hypocotyls of mangrove Bruguiera gymnorrhiza', Chemistry of Natural Compounds, 53(1), pp. 33-35. doi: 10.1007/s10600017-1904-8.

36. Yazaki, Y. and Hillis, W. E. (1976) 'Polyphenols of Eucalyptus globulus, E. Regnans and E. Deglupta', Phytochemistry, 15(7), pp. 1180-1182. doi: https://doi.org/10.1016/00319422(76)85129-1.

37. Yoon, Y., Kim, Y.-O., Jeon, W.-K., Park, H.-J. and Sung, H. J. (1999) 'Tanshinone IIA isolated from Salvia miltiorrhiza BUNGE induced apoptosis in HL60 human premyelocytic leukemia cell line', Journal of Ethnopharmacology, 68(1), pp. 121-127. doi: https://doi.org/10.1016/S0378-8741(99)00059-8.

38. Zehl, M., Braunberger, C., Conrad, J., Crnogorac, M., Krasteva, S., Vogler, B., Beifuss, U. and Krenn, L. (2011) 'Identification and quantification of flavonoids and ellagic acid derivatives in therapeutically important Drosera species by LC-DAD, LC-NMR, NMR, and LC-MS', Analytical and Bioanalytical Chemistry, 400(8), pp. 2565-2576. doi: 10.1007/s00216-011-4690-3.

39. Zhang, L., Liu, Yuanyan, Liu, Z., Wang, C., Song, Z., Liu, Yuxin, Dong, Y., Ning, Z. and $\mathrm{Lu}, \mathrm{A}$. (2016) 'Comparison of the roots of Salvia miltiorrhiza Bunge (Danshen) and its variety S. miltiorrhiza Bge f. Alba (Baihua Danshen) based on multi-wavelength HPLCfingerprinting and contents of nine active components', Analytical Methods. The Royal Society of Chemistry, 8(15), pp. 3171-3182. doi: 10.1039/C6AY00185H. 